Article

\title{
Adding Salt to Meals as a Risk Factor of Type 2 Diabetes Mellitus: A Case-Control Study
}

\author{
Lina Radzeviciene * and Rytas Ostrauskas \\ Institute of Endocrinology, Medical Academy, Lithuanian University of Health Sciences, Eiveniu 2, \\ 50009 Kaunas, Lithuania; rytas.ostrauskas@1smuni.lt \\ * Correspondence: lina_radzeviciene@yahoo.com; Tel.: +370-37-403-962
}

Received: 15 October 2016; Accepted: 10 January 2017; Published: 13 January 2017

\begin{abstract}
Objective: Type 2 diabetes mellitus (T2DM) is thought to arise from the complex interplay between genetic and environmental factors. It is important to identify modifiable risk factors that may help to reduce the risk of diabetes. Data on salt intake and the risk of type 2 diabetes are limited. The aim of this study was to assess the relationship between adding salt to prepared meals and the risk of type 2 diabetes. Methods: In a case-control study, we included 234 cases, all of whom were patients aged 35-86 years with a newly confirmed diagnosis of T2DM, and 468 controls that were free of the disease. Cases and controls (ratio 1:2) were matched by gender and age ( \pm 5 years). A questionnaire was used to collect information on possible risk factors for diabetes. Adding salt to prepared meals was assessed according to: Never, when there was not enough, or almost every time without tasting. The odds ratios (OR), and 95\% confidence intervals (CI) for type 2 diabetes was calculated using a conditional logistic regression. Results: The cases had a higher body mass index and a significantly lower education level compared to the controls. Variables such as waist circumference, body mass index, eating speed, smoking, family history of diabetes, arterial hypertension, plasma triglycerides, educational level, occupational status, morning exercise, marital status, daily urine sodium excretion, and daily energy intake were retained in the models as confounders. After adjusting for possible confounders, an approximately two-fold increased risk of type 2 diabetes was determined in subjects who add salt to prepared meals when "it is not enough" or "almost every time without tasting" (1.82; 95\% CI 1.19-2.78; $p=0.006)$ compared with never adding salt. Conclusion: Presented data suggest the possible relationship between additional adding of salt to prepared meals and an increased risk of type 2 diabetes.
\end{abstract}

Keywords: type 2 diabetes; salt; salt intake; risk factors; case-control study

\section{Introduction}

Diabetes mellitus is presently one of the biggest public health concerns. The emerging pandemic of patients with type 2 diabetes is driven by the combined effects of an aging population, rising levels of obesity, and inactivity [1]. Type 2 diabetes is thought to arise from the complex interplay between genetic and environmental factors, including highly calorific diets [2]. It is important to identify modifiable risk factors for type 2 diabetes mellitus, which may help to reduce the danger of the disease using prevention [3].

About 5000 years ago, the Chinese discovered that salt could be used to preserve foods [4]. Salt then became a large economic importance as it was possible to preserve foods during the winter, and allowed the development of settled communities [4]. Salt was the most taxed and traded commodity in the world, with intake reaching a peak around the 1870s [5]. However, with the invention of the freezer and the refrigerator, salt was no longer required as a preservative [5]. Salt intake had been declining, but with the recent massive increase in the consumption of highly salted processed foods, salt intake is again increasing [6]. 
The World Health Organization (WHO) suggests a global target of a maximum salt intake of $5 \mathrm{~g} /$ day for adults [7]. However, the average salt intake in most countries around the world is approximately 9 to $12 \mathrm{~g}$ /day [8]. For Lithuanian adults, the average intake of salt is approximately $8.75 \mathrm{~g} /$ day. Even $6.6 \%$ of Lithuanian inhabitants always add salt to prepared meals without preliminary tasting [9].

Consensus Action on Salt and Health (CASH), established in the United Kingdom in 1996, actively campaigns to raise awareness on the alleged harmful health effects of salt [10].

In the meantime, scientific literature data on salt intake and the risk of type 2 diabetes mellitus are limited. Therefore, the aim of this study was to assess the relationship between adding salt to prepared meals and the risk of type 2 diabetes mellitus.

\section{Materials and Methods}

\subsection{Participants and Setting}

A case-control study was carried over one year in the region-related to "Dainavos" outpatient clinic of Kaunas, Lithuania. The data source of our study was the inhabitants assigned to the outpatient clinic with primary and secondary level care of 72,000 0-96-year-old inhabitants.

The study included 234 cases, aged between 35 and 86 years, with a newly confirmed diagnosis of type 2 diabetes mellitus, according to the criteria of the World Health Organization, and were tracked over one full year [11]. All patients with type 2 diabetes were studied twice-once after the diagnosis of disease and once before receiving glucose lowering medications.

A total of 468 control subjects from people of the same clinic were recruited. Eligibility criteria were made corresponding to the, gender, age of controls, and a health status free of diabetes and other carbohydrate metabolism disorders. As exclusion criteria for controls, we used history; presence of established diabetes; or impaired glucose tolerance. Hospital staff or students' relatives were not involved as controls. All controls that had neither impaired glucose tolerance nor diabetes (after an oral 75 gram glucose tolerance test [11] was administered) were individually matched to cases by gender and age ( \pm 5 years). During the selection, 42 women and 27 men were recognized as not eligible as controls for the study. The ratio of cases to controls was 1:2.

\subsection{Ethical Approval}

The Kaunas Regional Bioethics Committee approved the design of the study (No. 65/2004). Written informed consent for participation in the study was obtained from all participants.

\subsection{Study Assessments}

Information on age, gender, family history of diabetes, arterial hypertension, plasma triglycerides, daily urine sodium concentration, education, occupational status, household income, marital status, nutrition habits, cigarette smoking, physical activity, and daily energy intake were assessed by a questionnaire designed by our research group. All subjects (cases and controls) were invited to complete the questionnaire themselves. The questionnaire had a good internal consistency of reliability and was applied in the study (Cronbach $\alpha$ (alpha) $=0.824)$. If there were reasons why someone was not able to complete the questionnaire themselves (e.g., poor general condition, poor eyesight, pathology of upper extremities, or a personal wish for assistance to fill in the questionnaire), interviews were conducted. Interviewers were specially trained and were not made aware of the study's hypothesis.

Adding salt to a prepared meal was assessed according to the maxims: Never add salt to a prepared meal, add salt to a prepared meal when there is not enough, and add salt to a prepared meal almost every time without tasting.

All participants were asked to fast for $12 \mathrm{~h}$ and to avoid smoking as well as heavy physical activity for at least $2 \mathrm{~h}$ before examinations. Using WHO guidelines [12], a single investigator took anthropometric measurements. Height was measured without shoes in centimeters $(0.1 \mathrm{~cm}$ accuracy). 
Weight was measured in light clothing in kilograms (0.5 kg accuracy). Body mass index (BMI) was calculated as weight $(\mathrm{kg}) /$ height $\left(\mathrm{m}^{2}\right)$ [13]. BMI was categorized as $18.5-24.9 \mathrm{~kg} / \mathrm{m}^{2}, 25-29.9 \mathrm{~kg} / \mathrm{m}^{2}$, or $\geq 30 \mathrm{~kg} / \mathrm{m}^{2}$ [14]. Waist circumference (WC) was measured by holding non-stretchable measuring tape, snugly around the waist, measured at the midpoint between the bottom rib and the top of the pelvic bones. Hip circumference was measured at the level of the great femur trochanter in centimeters (0.1 cm accuracy) [15]. WC was grouped according to those who were: Less than $80 \mathrm{~cm}$ for females and less than $94 \mathrm{~cm}$ for males, 80-88 cm for females and 94-102 cm for males, and greater than $88 \mathrm{~cm}$ for females and greater than $102 \mathrm{~cm}$ for males [16].

Blood pressure was measured with the subject in a sitting position, after at least five minutes of rest, from the left arm using a mercurial sphygmomanometer with a $2.0 \mathrm{~mm}$ mercurial column accuracy. Three measurements were taken at intervals of two minutes; the first of these was discarded and blood pressure was obtained from the mean of the latter two measurements. Arterial hypertension was defined as a systolic blood pressure of $\geq 140 \mathrm{mmHg}$, a diastolic blood pressure of $\geq 90 \mathrm{mmHg}$, and/or current use of antihypertensive medications [17].

Laboratory blood tests included fasting blood samples from subjects' elbow vein, and venous plasma samples were analyzed for glucose levels. Venous plasma glucose was estimated by the Glucose oxidase phenol 4-amino-antipyrine (GOD-PAP) method (Eppendorf Analyzer, Hamburg, Germany). In order to assess carbohydrate disorders, according to WHO recommendations, $75 \mathrm{~g}$ oral glucose tolerance tests were performed and evaluated in the study subjects [11].

Triglycerides were estimated by glycerol phosphate oxidase and peroxidase (GPO-PAP) enzymatic method (Randox analyzer, Antrim, UK).

Participants were given written instructions to collect a $24 \mathrm{~h}$ urine sample at home. The urine sodium concentration was determined using the ion selective electrode method (Easy Lyte analyzer, Bedford, USA). The urine sodium concentrations were grouped $<$ mean value and $>$ mean value.

A $24 \mathrm{~h}$ dietary recall was used for the assessment of dietary intake. The participants were asked to recall what they had eaten during the previous $24 \mathrm{~h}$. Nutrient values of food were calculated using the Lithuanian Food Composition Tables [18]. The energy intake was grouped <mean value and $>$ mean value.

Occupational status was assessed using the International Standard Classification of Occupations as: Higher education group - 1; qualified non-manual work group - 2; qualified manual work or less qualified non-manual work group-3; non-qualified manual work or non-qualified non-manual work group-4; pensioner-5; and unemployed or disabled-6 [19].

Levels of education (the number of years) were divided into three categories: Less than 10 years, 11-13 years, and more than 14 years.

Speed of eating was self-reported by the study subjects relative to other subjects with whom they were eating at the same table. Answers used were: Very slowly, relatively slower, the same as other subjects, relatively faster, and very fast. For the question, "How are you eating compared to other subjects?" the categories very slowly and relatively slower compared to other subjects were grouped into one category; relatively faster and very fast were placed in another category.

Smoking was assessed according to habits: Non-smoker, ex-smoker, occasional smoker, and current smoker.

A family history of diabetes was divided into two categories: First-degree relatives with a family history of diabetes and first-degree relatives without a family history of diabetes.

Arterial hypertension was grouped as yes or no.

Plasma triglycerides were grouped as $<1.7 \mathrm{mmol} / \mathrm{L}$ and $\geq 1.7 \mathrm{mmol} / \mathrm{L}$.

Morning exercise (duration at least $30 \mathrm{~min}$.) during the last 12 months: No, sometimes, and yes.

Marital status was assessed by grouping into four answers: Married/living together, divorced/separated, single, and widow/widower. 


\subsection{Statistical Analysis}

A conditional logistic regression was used to calculate the odds ratio (OR) and corresponding $95 \%$ confidence interval (CI) for diabetes mellitus in relation to exposures. Variables such as waist circumference, body mass index, eating speed, smoking, family history of diabetes, arterial hypertension, plasma triglycerides, daily urine sodium concentration, daily energy intake, educational level, occupational status, morning exercise, and marital status were retained in the models as confounders.

All reported trend test significance levels ( $p$-values) were two-sided. The $\chi^{2}$ test was utilized to calculate the differences between proportions. The level of significance was set at $5 \%$. All the calculations were performed using the standard STATA 7 software program.

\section{Results}

The characteristics of type 2 diabetic patients and of the control group are shown in Table 1. In our study, there were $28.21 \%$ men and $71.79 \%$ women. The mean age was 64.09 years (SD $=7.85$ ) (range: 39-86 years) for men and 65.23 years $(\mathrm{SD}=8.3)$ (range: $34-86$ years) for women. Cases (type 2 diabetic patients) had a significantly lower education level compared to controls. Their body mass index was higher than with controls. There were more controls without a first-degree family history of diabetes than compared with case subjects. The mean daily energy intake among case and control females were $8074.9 \pm 1179.3 \mathrm{~kJ}$ (mean \pm standard deviation) and $8074.5 \pm 1177.4 \mathrm{~kJ}(p>0.05)$, and among males, correspondingly, $11,777.4 \pm 3162.8 \mathrm{~kJ}$ vs. $11,706.0 \pm 3202.4 \mathrm{~kJ}(p>0.05)$. The mean daily urine excretion among cases was not significantly different compared with controls $(165.5 \pm 50.7 \mathrm{mmol} / \mathrm{L}$ vs. $165.2 \pm 40.34 \mathrm{mmol} / \mathrm{L})$.

Table 1. Characteristics of cases and controls.

\begin{tabular}{|c|c|c|c|c|c|c|}
\hline \multirow{2}{*}{ Variable } & \multirow{2}{*}{ Category } & \multicolumn{2}{|c|}{ Cases } & \multicolumn{2}{|c|}{ Controls } & \multirow{2}{*}{$\begin{array}{c}p \text {-Value } \\
\text { for } \chi^{2}\end{array}$} \\
\hline & & $n$ & $\%$ & $n$ & $\%$ & \\
\hline \multirow[b]{2}{*}{ Gender } & Males & 66 & 28.21 & 132 & 28.21 & matched \\
\hline & Females & 168 & 71.79 & 336 & 71.79 & \\
\hline \multirow{4}{*}{ Age (years) } & $\leq 44$ & 12 & 5.13 & 22 & 4.70 & matched \\
\hline & $4 \overline{5}-54$ & 21 & 8.97 & 44 & 9.40 & \\
\hline & $55-64$ & 90 & 38.46 & 178 & 38.03 & \\
\hline & $\geq 65$ & 111 & 47.44 & 224 & 47.86 & \\
\hline \multirow{2}{*}{$\begin{array}{l}\text { Family history of } \\
\text { diabetes }\end{array}$} & First-degree relatives without family history of diabetes & 166 & 70.94 & 422 & 90.17 & \\
\hline & First-degree relatives with positive family history of diabetes & 68 & 29.06 & 46 & 9.83 & $<0.001$ \\
\hline \multirow{3}{*}{ BMI $\left(\mathrm{kg} / \mathrm{m}^{2}\right)$} & $\leq 24.9$ & 21 & 8.97 & 124 & 26.50 & \\
\hline & $25-29.99$ & 57 & 24.36 & 185 & 39.53 & \\
\hline & $\geq 30$ & 156 & 66.67 & 159 & 33.97 & $<0.001$ \\
\hline \multirow{6}{*}{$\begin{array}{l}\text { Waist circumference } \\
\qquad(\mathrm{cm})\end{array}$} & Females $<80$ & & & & & \\
\hline & Males < 94 & 18 & 7.69 & 111 & 23.72 & \\
\hline & Females $80-88$ & & & & & \\
\hline & Males 94-102 & 20 & 8.55 & 118 & 25.21 & \\
\hline & Females $>88$ & 196 & 83.76 & 239 & 51.07 & $<0.001$ \\
\hline & Males > 102 & 190 & $83 . / 6$ & 239 & 31.07 & $<0.001$ \\
\hline \multirow{3}{*}{ Education (years) } & $\leq 10$ & 115 & 49.15 & 157 & 33.55 & \\
\hline & $11-13$ & 70 & 29.91 & 192 & 41.03 & \\
\hline & $\geq 14$ & 49 & 20.94 & 119 & 25.43 & $<0.001$ \\
\hline \multirow{4}{*}{ Marital status } & Married & 137 & 58.55 & 296 & 63.25 & \\
\hline & Divorced/separated & 16 & 6.84 & 40 & 8.55 & \\
\hline & Single & 13 & 5.56 & 25 & 5.34 & \\
\hline & Widowed & 68 & 29.06 & 107 & 22.86 & NS \\
\hline \multirow{6}{*}{ Occupational status } & Higher education & 16 & 6.84 & 46 & 9.83 & \\
\hline & Qualified non manual work & 9 & 3.85 & 16 & 3.42 & \\
\hline & Qualified manual work or less qualified non-manual work & 12 & 5.13 & 31 & 6.62 & \\
\hline & Non-qualified manual work or non-qualified non-manual work & 7 & 2.99 & 28 & 5.98 & \\
\hline & Pensioner & 159 & 67.95 & 306 & 65.38 & \\
\hline & Unemployed or disabled & 31 & 13.42 & 41 & 8.76 & NS \\
\hline
\end{tabular}


Table 1. Cont.

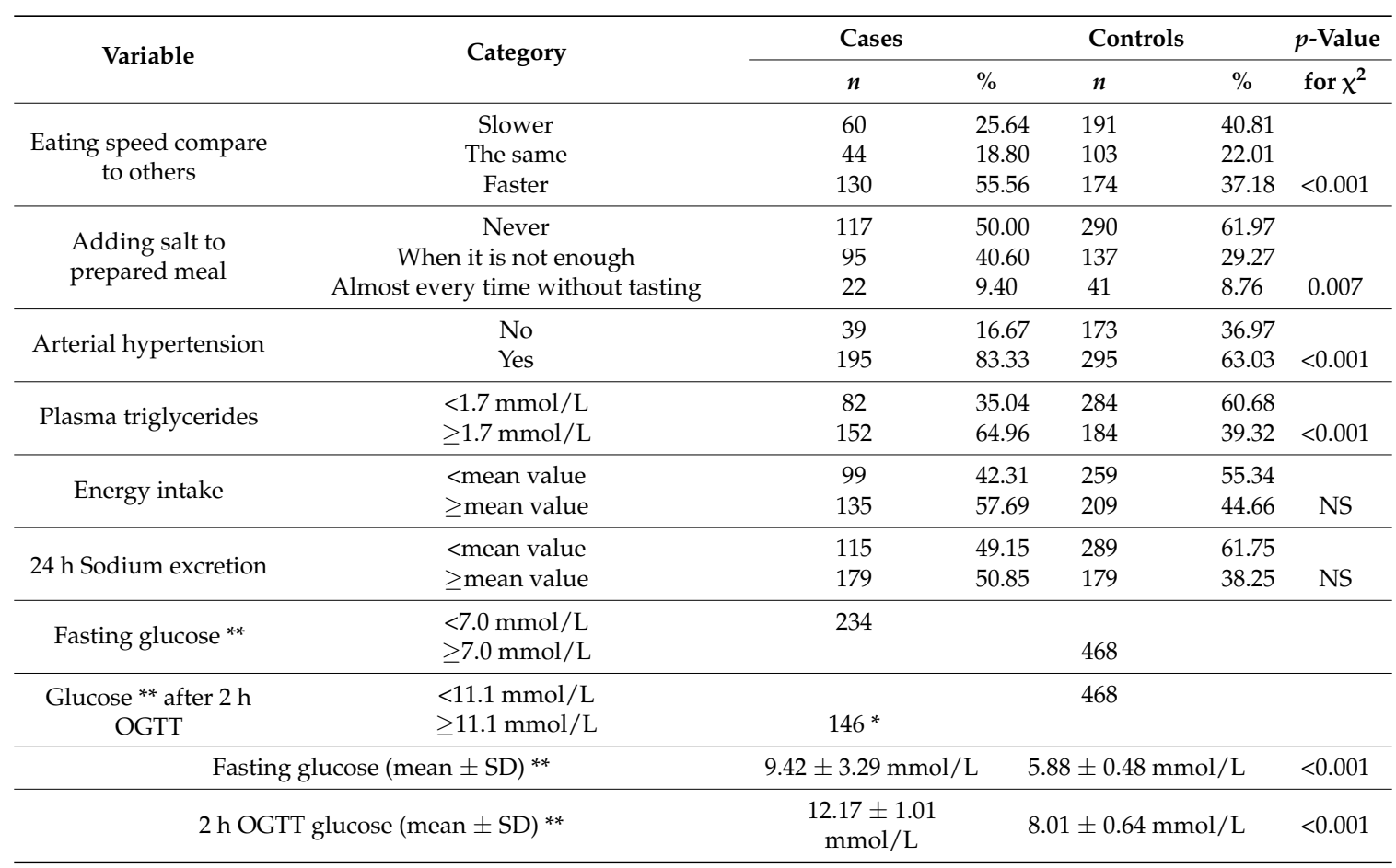

NS: not significant; SD: standard deviation; OGTT: oral glucose tolerance test; ${ }^{*}$ for 88 patients diagnosis of diabetes was made by twice repeating high values of fasting glucose; ${ }^{* *}$ in venous blood plasma.

Univariate regression showed that subjects who were adding salt to a prepared meal when there was not enough, or almost every time without tasting, were associated with a higher risk of type 2 diabetes mellitus (crude OR $=1.63 ; 95 \%$ CI 1.19-2.25). A dose-response relationship has been defined between the risk of this disease and adding salt to a prepared meal.

Variables, such as waist circumference, body mass index, eating speed, smoking, family history of diabetes, arterial hypertension, plasma triglycerides, daily urine sodium concentration, daily energy intake, educational level, occupational status, morning exercise, and marital status, were retained in the models as confounders.

Data of unadjusted odds ratios and 95\% confidence interval for type 2 diabetes mellitus are presented in Table 2. Data of multivariate logistic regression, showing the relationship between type 2 diabetes mellitus and adding salt to prepare meals, are presented in Table 3 . After adjusting for a waist circumference, body mass index, eating speed, smoking, family history of diabetes, arterial hypertension, plasma triglycerides, daily urine sodium concentration, daily energy intake, educational level, occupational status, morning exercise, and marital status, we found an approximately two-fold increased risk of type 2 diabetes mellitus in subjects who add salt to prepared meals when there is not enough or almost every time without tasting $(1.82 ; 95 \%$ CI 1.19-2.78; $p=0.006)$ compared with subjects who never add salt to prepared meals. 
Table 2. Unadjusted odds ratios and 95\% confidence interval for type 2 diabetes mellitus.

\begin{tabular}{cccc}
\hline Confounders & Odds Ratio & $\mathbf{( 9 5 \% ~ C I ) ~}$ & $p$ \\
\hline Adding salt to prepared meal & 1.63 & $1.19-2.25$ & 0.003 \\
Waist circumference & 5.02 & $3.40-7.44$ & $<0.001$ \\
Family history of diabetes & 3.76 & $2.48-5.69$ & $<0.001$ \\
Arterial hypertension & 2.93 & $1.98-4.33$ & $<0.001$ \\
Plasma triglycerides & 2.86 & $2.06-3.97$ & $<0.001$ \\
Body mass index & 2.61 & $2.05-3.33$ & $<0.001$ \\
Eating speed & 1.34 & $1.20-1.51$ & $<0.001$ \\
Smoking & 1.24 & $1.05-1.45$ & 0.009 \\
Occupational status & 1.51 & $1.02-2.22$ & 0.039 \\
Marital status & 1.05 & $0.84-1.31$ & 0.650 \\
Daily energy intake & 0.98 & $0.71-1.34$ & 0.881 \\
Daily urine sodium concentration & 0.95 & $0.56-1.60$ & 0.846 \\
Morning exercises & 0.76 & $0.57-1.02$ & 0.071 \\
Educational level & 0.71 & $0.58-0.88$ & 0.001 \\
\hline
\end{tabular}

Table 3. The odds ratios and $95 \%$ confidence interval for type 2 diabetes mellitus in relation to adding salt to a prepared meal.

\begin{tabular}{|c|c|c|c|c|c|c|c|c|}
\hline \multirow{2}{*}{ Variable } & \multirow{2}{*}{ Category } & \multicolumn{2}{|c|}{ Cases } & \multicolumn{2}{|c|}{ Controls } & \multirow{2}{*}{$\begin{array}{c}\mathrm{OR}^{1} \\
(95 \% \mathrm{CI}) \\
p\end{array}$} & \multirow{2}{*}{$\begin{array}{c}\begin{array}{c}\mathrm{OR}^{2} \\
(95 \% \mathrm{CI})\end{array} \\
p\end{array}$} & \multirow{2}{*}{$\begin{array}{c}\mathrm{OR}^{3} \\
(95 \% \mathrm{CI})\end{array}$} \\
\hline & & $n$ & $\%$ & $n$ & $\%$ & & & \\
\hline \multirow[b]{2}{*}{$\begin{array}{l}\text { Adding salt to } \\
\text { prepared meal }\end{array}$} & Never & 117 & 50.00 & 290 & 61.97 & 1.00 & 1.00 & 1.00 \\
\hline & $\begin{array}{l}\text { When there is not enough or } \\
\text { almost every time without tasting }\end{array}$ & 117 & 50.00 & 178 & 38.03 & $\begin{array}{l}1.68 \\
(1.15-2.46) \\
p=0.007\end{array}$ & $\begin{array}{c}1.71 \\
(1.14-2.56) \\
p=0.009\end{array}$ & $\begin{array}{c}1.82 \\
(1.19-2.78) \\
p=0.006\end{array}$ \\
\hline
\end{tabular}

$\mathrm{OR}^{1}$ adjusted for waist circumference, body mass index, and family history of diabetes; $\mathrm{OR}^{2}$ adjusted for waist circumference, body mass index, family history of diabetes, daily energy intake, daily urine sodium concentration, eating speed, morning exercise, arterial hypertension, and plasma triglycerides; $\mathrm{OR}^{3}$ adjusted for waist circumference, body mass index, family history of diabetes, daily energy intake, daily urine sodium concentration, eating speed, morning exercise, arterial hypertension, plasma triglycerides, smoking, educational level, occupational, and marital statuses.

\section{Discussion}

Our data showed that subjects who add salt to prepared meals when there is not enough, or almost every time without tasting have about a two-fold higher risk of developing type 2 diabetes mellitus compared to subjects who never add salt to prepared meals. The main achievement of our study was the case group that was not affected by glucose lowering treatment. The main weakness is the lack of data about the direct effect of salt on blood glucose levels. However, excess of salt can raise other risk factors for diabetes.

A prospective study in 932 Finnish men and 1003 women, with an average follow-up of 18 years, demonstrated that a higher salt intake (measured by $24 \mathrm{~h}$ urinary sodium) was associated with an increased risk of type 2 diabetes independent of potential confounding factors including physical activity, obesity, and hypertension [20]. The mechanism of the association between high intake of sodium and the risk of type 2 diabetes is not well understood.

The WHO recommends for adults to ingest $2.0 \mathrm{~g} /$ day of sodium (which corresponds to $5 \mathrm{~g}$ of salt/day) based on an assessment of the best available evidence [7]. The primary source of sodium in diet is from salt $(\mathrm{NaCl})$. The terms salt and sodium are often used synonymously, although, on a weight basis, salt is comprised of $40 \%$ sodium and $60 \%$ chloride; $1 \mathrm{~g}$ of sodium is equivalent to $2.55 \mathrm{~g}$ of salt; $1 \mathrm{mmol}$ of sodium is equivalent to $23 \mathrm{mg}$ of sodium; and $1 \mathrm{~g}$ of salt is equivalent to $17 \mathrm{mmol}$ of sodium [21].

Many observational epidemiological studies conducted worldwide have linked high salt intake and hypertension. The causal relation between habitual dietary salt intake and blood pressure has been established through experimental, epidemiological, migration, and intervention studies [22-24]. 
The first major global study on sodium intake: INTERSALT (10,079 study subjects from 52 centers around the world) demonstrated a significant association with blood pressure, as well as an increase in blood pressure with age. In that study, sodium intake was estimated from $24 \mathrm{~h}$ urinary excretion and ranged from $0.2 \mathrm{mmol} / 24 \mathrm{~h}$ (Yanomamo Indians, Brazil) to $242 \mathrm{mmol} / 24 \mathrm{~h}$ (Tianjin, North China) [25]. In the WHO-CARDIAC (World Health Organization Cardiovascular Diseases and Alimentary Comparison) study, performed in 17 countries, $24 \mathrm{~h}$ sodium excretion was positively associated with blood pressure among post-menopausal women aged $48-56$ years. [26]. The results from epidemiological studies have indicated that subjects with hypertension are more likely to develop type 2 diabetes. The Augsburg surveys, performed between 1984 and 1995, based on 3052 men and 3114 women (aged 35 to 74 years) who participated in one of the three MONICA (Monitoring of Trends and Determinants in Cardiovascular Disease) surveys showed that hypertension was strongly associated with diabetes in men and women [27].

Overweight and obese people usually eat more food than normal-weight people along with a larger quantity of food intake; they also get more sodium. It could be hypothesized that high sodium intake might increase the risk of type 2 diabetes partly through weight gain and hypertension [28,29]. Overweight and obesity are often associated with high blood pressure, and are causally involved in the development of hypertension $[16,30,31]$. A high salt intake has been suggested as an indirect cause of obesity through the effect it has on soft drink consumption [31]. Salt makes you thirsty and increases the amount of fluid you drink. A reduction in salt intake by $1 \mathrm{~g} / \mathrm{d}$ was found to be associated with a difference of $-100 \mathrm{~g} /$ day in total fluid consumption and $-27 \mathrm{~g} /$ day in sugar-sweetened soft drinks consumption [32]. It has been estimated that a reduction in salt intake from $10 \mathrm{~g} /$ day to the WHO recommended level of $5 \mathrm{~g} /$ day would reduce fluid consumption by $\approx 350 \mathrm{~mL} /$ day [31]. A study that analyzed the sales of salt and carbonated beverages in the USA between 1985 and 2005 showed a close link between the two, as well as a parallel link with obesity [31].

A randomized community-based intervention trial that was carried out with 550 individuals in Japan demonstrated that dietary counseling for one year reduced salt intake by $2.3 \mathrm{~g} /$ day, as measured by $24 \mathrm{~h}$ urinary sodium, and this was associated with a decrease of $3.1 \mathrm{mmHg}$ in systolic blood pressure [33]. A reduction in salt from the current average intake of 9-12 g/day to the recommended level of 5-6 g/day will have a major effect on blood pressure and cardiovascular disease; furthermore, it may have other beneficial effects on health [5].

This study has some limitations. The first limitation that needs to be acknowledged and addressed regarding this study is that adding salt to prepared meals was self-reported by subjects, and we cannot exclude reporting bias in the present study. The analyses should be adjusted for the sodium from food and the sodium added during the cooking process. Without this adjustment, the relationship between adding salt to prepared meals and type 2 diabetes remains an hypothesis. Second, the renin-angiotensin-aldosterone system and electrolyte parameters were not studied. Aldosterone plays an important role in glucose metabolism in both animals and humans. The renin-angiotensin-aldosterone system's deleterious axis increases the production of inflammatory cytokines and raises oxidative stress; consequently, exacerbating insulin resistance and decreasing insulin secretion [34]. Aldosterone impairs insulin receptor signaling by altering the phosphatidylinositol 3-kinase/nitric oxide pathway, by inducing oxidative stress, and by crosstalk between the insulin receptor and the insulin-like growth factor-1 receptor [34-36]. The beneficial axis promotes adipogenesis, blocks the production of inflammatory cytokines, and lowers oxidative stress thereby improving insulin sensitivity and secretion [37].

Recently, investigations have demonstrated that excessive salt intake has a pivotal role in the development of inflammatory reactions [38]. Studies have shown that excessive dietary salt intake induced severe inflammatory reactions through augmentation of T-helper 17 cells and their highly inflammatory cytokines [38]. Substantial progress has been made over the last 50 years in studies examining the neural and hormonal basis of thirst and salt appetite [39]. Some of the neurotransmitters and hormones, including the brain area, play a role in water and electrolyte balance [39]. However, 
further research should be conducted to elucidate the role of high salt intake in the pathophysiology related to disturbances of carbohydrate regulation.

Food can be salted when required for the conservation of food stocks. It is common in countries where season changes reflect significant fluctuations in temperature. Eastern European populations usually consume salted or ready-to-cook meat and fish products, and a great deal of pickled vegetables. Frequent consumption of salted foods may become a habit, which has prompted the development of new taste habits in human mentality. Taste habits become powerful and irresistible. Therefore, even without trying to taste salted food, it, once again, is further salted. This habit can be changed with upbringing and willpower. If people know that excessive salt intake can lead not only to an increase in blood pressure, cardiovascular disease, and renal disease emergence, but also to an increased risk of diabetes. This can become an additional stimulus for a reduction in salt consumption.

\section{Conclusions}

The findings in this study demonstrate a significant relationship between lifestyle and the potential to develop type 2 diabetes mellitus. The presented data has raised the hypothesis of a possible relationship between adding salt to a prepared meal and an increased risk of type 2 diabetes mellitus. This may be related to negative type 2 diabetes-inducing habits.

Acknowledgments: The authors thank the participants for their contributions to the study. We appreciate the English grammar correction by Arnold Kincius. This study did not receive any funding.

Author Contributions: Lina Radzeviciene and Rytas Ostrauskas formulated the research questions, designed the study, carried out the study, analyzed the data, and wrote the article.

Conflicts of Interest: The authors declare no conflicts of interest.

\section{References}

1. Van Dieren, S.; Beulens, J.W.; van der Schouw, Y.T.; Grobbee, D.E.; Neal, B. The global burden of diabetes and its complications: An emerging pandemic. Eur. J. Cardiovasc. Prev. Rehabil. 2010, 17 (Suppl. S1), S3-S8. [PubMed]

2. Naser, K.A.; Gruber, A.; Thomson, G.A. The emerging pandemic of obesity and diabetes: Are we doing enough to prevent a disaster? Int. J. Clin. Pract. 2006, 60, 1093-1097. [CrossRef] [PubMed]

3. Følling, I.S.; Solbjør, M.; Midthjell, K.; Kulseng, B.; Helvik, A.S. Exploring lifestyle and risk in preventing type 2 diabetes-a nested qualitative study of older participants in a lifestyle intervention program (VEND-RISK). BMC Public Health 2016, 16, 876. [CrossRef]

4. Ha, S.K. Dietary salt intake and hypertension. Electrol. Blood Press. 2014, 12, 7-18. [CrossRef] [PubMed]

5. He, F.J.; MacGregor, G.A. A comprehensive review on salt and health and current experience of worldwide salt reduction programmes. J. Hum. Hypertens. 2009, 23, 363-384. [CrossRef] [PubMed]

6. He, F.J.; MacGregor, G.A. Reducing population salt intake worldwide: From evidence to implementation. Prog. Cardiovasc. Dis. 2010, 52, 363-382. [CrossRef] [PubMed]

7. Joint World Health Organization/Food and Agricultural organization Expert Consultation. Diet, Nutrition and the Prevention of Chronic Diseases; WHO Technical Report Series, No. 916; World Health Organization: Geneva, Switzerland, 2003; pp. 1-149. Available online: http://www.who.int/dietphysicalactivity/ publications/trs916/en/ (accessed on 18 September 2016).

8. Brown, I.J.; Tzoulaki, I.; Candeias, V.; Elliott, P. Salt intakes around the world: Implications for public health. Int. J. Epidemiol. 2009, 38, 791-813. [CrossRef] [PubMed]

9. Barzda, A.; Bartkeviciute, R.; Stukas, R.; Satkute, R.; Abramavicius, A. Lithuanian adult population nutrition trends during the past decade. Sveik. Moksl. 2010, 1, 2831-2835. (In Lithuanian)

10. CASH: Consensus Action on Salt and Health. Available online: http://www.actiononsalt.org.uk (accessed on 7 March 2013).

11. Alberti, K.G.; Zimmet, P.Z. Definition, diagnosis and classification of diabetes mellitus and its complications. Part 1: Diagnosis and classification of diabetes mellitus provisional report of a WHO consultation. Diabet. Med. 1998, 15, 539-553. [CrossRef] 
12. World Health Organization Expert Committee. Physical Status: The Use and Interpretation of Anthropometry; WHO Technical Report Series, No. 854; World Health Organization: Geneva, Switzerland, 1995; pp. 1-452. Available online: http://apps.who.int/iris/bitstream/10665/37003/1/WHO_TRS_854.pdf (accessed on 12 November 2015).

13. Garrow, J.S.; Webster, J. Quetelet's index (W/H2) as a measure of fatness. Int. J. Obes. 1985, 9, 147-153. [PubMed]

14. World Health Organization Consultation. Obesity: Preventing and Managing the Global Epidemic; WHO Technical Report Series, No. 894; World Health Organization: Geneva, Switzerland, 2000; pp. 1-253. Available online: http://www.who.int/nutrition/publications/obesity/WHO_TRS_894/en/ (accessed on 12 November 2015).

15. Han, T.S.; McNeill, G.; Seidell, J.C.; Lean, M.E. Predicting intra-abdominal fatness from anthropometric measures: The influence of stature. Int. J. Obes. Relat. Metab. Disord. 1997, 21, 587-593. [CrossRef] [PubMed]

16. Clinical Guidelines on the Identification, Evaluation, and Treatment of Overweight and Obesity in Adults. Obes. Res. 1998, 6 (Suppl. S2), 51S-209S.

17. The Fifth Report of the Joint National Committee on Detection, Evaluation, and Treatment of High Blood Pressure (JNC V). Arch. Intern. Med. 1993, 153, 154-183.

18. Mityba, M.D. Vilnius; Vilniaus Universitetas: Vilnius, Lithuania, 1996; pp. 1-192. (In Lithuanian)

19. International Labour Organization. International Standard Classification of Occupations 2008 (ISCO-08): Structure, Group Definitions and Correspondence Tables; International Labour Office: Geneva, Switzerland, 2012; pp. 1-420. Available online: http://www.ilo.org/wcmsp5/groups/public/dgreports/dcomm/publ/ documents/publication/wcms_172572.pdf (accessed on 21 September 2016).

20. Hu, G.; Jousilahti, P.; Peltonen, M.; Lindström, J.; Tuomilehto, J. Urinary sodium and potassium excretion and the risk of type 2 diabetes: A prospective study in Finland. Diabetologia 2005, 48, 1477-1483. [CrossRef] [PubMed]

21. Scientific Advisory Committee on Nutrition. Salt and Health; The Stationery Office: London, UK, 2003; pp. 1-118. Available online: http://www.sacn.gov.uk/pdfs/sacn_salt_final.pdf (accessed on 16 November 2014).

22. Strazzullo, P.; D’Elia, L.; Kandala, N.B.; Cappuccio, F.P. Salt intake, stroke, and cardiovascular disease: Meta-analysis of prospective studies. BMJ 2009, 339, b4567. [CrossRef] [PubMed]

23. Aaron, K.J.; Sanders, P.W. Role of dietary salt and potassium intake in cardiovascular health and disease: A review of the evidence. Mayo Clin. Proc. 2013, 88, 987-995. [CrossRef] [PubMed]

24. Stolarz-Skrzypek, K.; Bednarski, A.; Czarnecka, D.; Kawecka-Jaszcz, K.; Staessen, J.A. Sodium and potassium and the pathogenesis of hypertension. Curr. Hypertens. Rep. 2013, 15, 122-130. [CrossRef] [PubMed]

25. Intersalt Cooperative Research Group. Intersalt: An international study of electrolyte excretion and blood pressure. Results for $24 \mathrm{~h}$ urinary sodium and potassium excretion. BMJ 1988, 297, 319-328.

26. Yamori, Y.; Liu, L.; Ikeda, K.; Mizushima, S.; Nara, Y.; Simpson, F.O.; WHO Cardiovascular Diseases and Alimentary Comparison (WHO-CARDIAC) Study. Different associations of blood pressure with 24-hour urinary sodium excretion among pre- and post-menopausal women. J. Hypertens. 2001, 19, 535-538. [CrossRef] [PubMed]

27. Meisinger, C.; Thorand, B.; Schneider, A.; Stieber, J.; Döring, A.; Löwel, H. Sex differences in risk factors for incident type 2 diabetes mellitus: The MONICA Augsburg cohort study. Arch. Intern. Med. 2002, 162, 82-89. [CrossRef] [PubMed]

28. Elliott, P.; Stamler, J.; Nichols, R.; Dyer, A.R.; Stamler, R.; Kesteloot, H.; Marmot, M. Intersalt revisited: Further analyses of 24 hour sodium excretion and blood pressure within and across populations. Intersalt Cooperative Research Group. BMJ 1996, 312, 1249-1253. [CrossRef] [PubMed]

29. He, F.J.; Markandu, N.D.; Sagnella, G.A.; MacGregor, G.A. Effect of salt intake on renal excretion of water in humans. Hypertension 2001, 38, 317-320. [CrossRef] [PubMed]

30. Susic, D.; Varagic, J. Obesity: A Perspective from Hypertension. Med. Clin. N. Am. 2017, 101, $139-157$. [CrossRef] [PubMed]

31. Karppanen, H.; Mervaala, E. Sodium intake and hypertension. Prog. Cardiovasc. Dis. 2006, 49, 59-75. [CrossRef] [PubMed]

32. He, F.J.; Marrero, N.M.; MacGregor, G.A. Salt intake is related to soft drink consumption in children and adolescents: A link to obesity? Hypertension 2008, 51, 629-634. [CrossRef] [PubMed] 
33. Takahashi, Y.; Sasaki, S.; Okubo, S.; Hayashi, M.; Tsugane, S. Blood pressure change in a free-living population-based dietary modification study in Japan. J. Hypertens. 2006, 24, 451-458. [CrossRef] [PubMed]

34. Bender, S.B.; McGraw, A.P.; Jaffe, I.Z.; Sowers, J.R. Mineralocorticoid receptor-mediated vascular insulin resistance: An early contributor to diabetes-related vascular disease? Diabetes 2013, 62, 313-319. [CrossRef] [PubMed]

35. Bruder-Nascimento, T.; da Silva, M.A.; Tostes, R.C. The involvement of aldosterone on vascular insulin resistance: Implications in obesity and type 2 diabetes. Diabetol. Metab. Syndr. 2014, 6, 90. [CrossRef] [PubMed]

36. Ilatovskaya, D.V.; Levchenko, V.; Brands, M.W.; Pavlov, T.S.; Staruschenko, A. Cross-talk between insulin and IGF-1 receptors in the cortical collecting duct principal cells: Implication for ENaC-mediated Na+ reabsorption. Am. J. Physiol. Ren. Physiol. 2015, 308, F713-F719. [CrossRef] [PubMed]

37. Favre, G.A.; Esnault, V.L.; Van Obberghen, E. Modulation of glucose metabolism by the renin-angiotensin-aldosterone system. Am. J. Physiol. Endocrinol. Metab. 2015, 308, E435-E449. [CrossRef] [PubMed]

38. Kleinewietfeld, M.; Manzel, A.; Titze, J.; Kvakan, H.; Yosef, N.; Linker, R.A.; Muller, D.N.; Hafler, D.A. Sodium chloride drives autoimmune disease by the induction of pathogenic TH17 cells. Nature 2013, 496, 518-522. [CrossRef] [PubMed]

39. Sakai, R.R. The future of research on thirst and salt appetite. Appetite 2004, 42, 15-19. [CrossRef] [PubMed]

(C) 2017 by the authors; licensee MDPI, Basel, Switzerland. This article is an open access article distributed under the terms and conditions of the Creative Commons Attribution (CC-BY) license (http://creativecommons.org/licenses/by/4.0/). 